\title{
Evaluation and Selection of 3PL Provider Using Fuzzy AHP and Grey TOPSIS in Group Decision Making
}

\author{
Annisa Kesy Garside ${ }^{1, \text { a) }}$ and Thomy Eko Saputro ${ }^{1}$ \\ ${ }^{1}$ Department of Industrial Engineering, University of Muhammadiyah Malang \\ Malang, Indonesia \\ a) Corresponding author: annisa_garside@yahoo.com
}

\begin{abstract}
Selection of a 3PL provider is a problem of multi criteria decision making, where the decision maker has to select several 3PL provider alternatives based on several evaluation criteria. A decision maker will have difficulty to express judgments in exact numerical values due to the fact that information is often incomplete and the decision environment is uncertain. This paper presents an integrated fuzzy AHP and Grey TOPSIS for the evaluation and selection of 3PL provider method. Fuzzy AHP is used to determine the importance weight of evaluation criteria. For final selection, grey TOPSIS is used to evaluate the alternatives and obtain the overall performance which is measured as closeness coefficient. This method is applied to solve the selection of 3PL provider at PT. X. Five criterias and twelve sub-criterias were determined and then the best alternative among four 3PL providers was selected by proposed method.
\end{abstract}

\section{INTRODUCTION}

Many companies outsourced their logistic activity to Third Party Logistic (3PL) providers in order to focus on their core competence. Besides, the companies also receive several other benefits such as reduced logistics cost and fixed logistics assets, and improved the service. For those reasons, the suitable 3PL provider should be correctly selected, or otherwise the companies will experience low quality logistic services and non-fulfillment contracts. This may resulted in bad reputation and trust of the company. Therefore the suitable selection of 3PL provider is an important factor that will determine the company's logistic performance.

The evaluation and selection of 3PL providers is Multi-Criteria Decision Making (MCDM) problem whereas a decision maker has to select the best alternative based on several evaluation criteria. At the moment there are many studies performed by researchers and practitioners offering different method and evaluation criteria. A comprehensive study on different methods used in the 3PL provider selection was conducted by [1]. The methods commonly used are Analiytic hierarchy process (AHP) and Fuzzy AHP, Analytic network process (ANP), Technique for order preference by similarity to ideal solution (TOPSIS), and Data envelopment analysis (DEA). On the other side, the evaluation criteria for the selection of 3PL providers have been many times discussed in the previous researches. The relevant criteria for the selection of a provider have been compiled by [2]. Another research provides more detailed 27 criterias covering the general company considerations, quality, client relationship, capabilities, and labor relations in 3PL provider selection on a leading Turkish automotive company. An integrated criteria list (followed by sets of sub-criteria) has been modeled for evaluation and selection of 3PL providers by [4] and [5].

In conventional MCDM, the ratings and weights of criterias are known with their exact numerical value. Decision makers often have difficulty in expressing preferences appropriately. This is due to several factors including incompleteness and uncertainty of information. In recent years, a fuzzy-based approach has been proposed to solve 3PL provider selection under uncertainty. One of method often used is fuzzy AHP [3,4]. In some studies, fuzzy AHP is integrated with TOPSIS or fuzzy TOPSIS to select the best 3PL provider $[1,6,7]$. The usage of fuzzy AHP weights in TOPSIS makes the decisions more realistic and reliable.

3rd International Materials, Industrial and Manufacturing Engineering Conference (MIMEC2017) AIP Conf. Proc. 1902, 020056-1-020056-10; https://doi.org/10.1063/1.5010673 Published by AIP Publishing. 978-0-7354-1590-4/\$30.00 
PT. $\mathrm{X}$ is one of the company that produces steel pipe and tube. Currently this company is considering the contract with several 3PL providers to handle its inbound and outbound logistics operation. So far the logistic department has not been using any quantitative method to select 3PL provider but instead the selection has already been based on several criteria. In this paper, we propose an integrated fuzzy AHP and Grey TOPSIS to evaluate and select 3PL providers according to a decision making group in PT. X. Grey theory [8] was proposed by Deng in 1982, It is a new method used to solve uncertainty problems with discrete data and incomplete information [9]. Combining fuzzy AHP with Grey TOPSIS will provide more realistic and reasonable judgments for logistic department of PT X.

\section{LITERATURE}

\section{Fuzzy analytic hierarchy process (Fuzzy AHP)}

The triangular fuzzy numbers are used in the pairwise comparison process to express subjective judgments in fuzzy AHP. It is defined by three real numbers, expressed as $(1, \mathrm{~m}, \mathrm{u})$. The $1, \mathrm{~m}$, and $\mathrm{u}$ parameters indicate the smallest possible value, the most promising value, and the largest possible value which describes a fuzzy event. The steps of fuzzy AHP, based on [10] as follows:

Step 1: The value of fuzzy synthetic extent with respect to the i-th object is defined as :

$$
S_{i}=\sum_{j=1}^{m} M i j \otimes\left[\sum_{i=1}^{n} \sum_{j=1}^{m} M i j\right]^{-1}
$$

Where

$$
\begin{aligned}
& \sum_{j=1}^{m} M i j=\left(\sum_{j=1}^{m} 1 j, \sum_{j=1}^{m} m_{j}, \sum_{j=1}^{m} u_{j}\right) \\
& \sum_{i=1}^{n} \sum_{j=1}^{m} M_{i j}=\left(\sum_{i=1}^{n} 1_{i}, \sum_{i=1}^{n} m_{i}, \sum_{i=1}^{n} u_{i}\right), \text { and } \\
& {\left[\sum_{i=1}^{n} \sum_{j=1}^{m} M_{i j}\right]^{-1}=\left(1 / \sum_{i=1}^{n} u_{i}, 1 / \sum_{i=1}^{n} m_{i}, 1 / \sum_{i=1}^{n} 1_{i}\right)}
\end{aligned}
$$

Step 2: The degree of possibility of $\mathrm{M}_{1} \geq \mathrm{M}_{2}$ is defined as:

$$
V\left(M_{1} \geq M_{2}\right)=\sup _{x \geq y}\left\lfloor\min \left(\left(\mu_{M 1}(x)\right),\left(\mu_{M 2}(y)\right)\right\rfloor\right.
$$

When an $(\mathrm{x}, \mathrm{y})$ pair exists such that $\mathrm{x} \geq \mathrm{y}$ and $\mu_{\mathrm{M}_{1}}(\mathrm{x})=\mu_{\mathrm{M}_{2}}(\mathrm{y})=1$ then we have $\mathrm{V}\left(\mathrm{M}_{1} \geq \mathrm{M}_{2}\right)=1$. Since $\mathrm{M}$ dan $\mathrm{M}$ are convex fuzzy number then it become :

$$
\begin{aligned}
& V\left(M_{1} \geq M_{2}\right)=1 \text { if } m_{1} \geq m_{2}, \\
& V\left(M_{2} \geq M_{1}\right)=\operatorname{hgt}\left(M_{1} \cap M_{2}\right)=\mu_{M 2}(d),
\end{aligned}
$$

Which $d$ is the ordinate of the highest intersection point $D$ between $\mu_{M_{1}}$ and $\mu_{M_{2}}$ (see Fig. 1). When $M_{1}=\left(l_{1}, m_{1}\right.$, $\left.\mathrm{u}_{1}\right)$ and $\mathrm{M}_{2}=\left(\mathrm{l}_{2}, \mathrm{~m}_{2}, \mathrm{u}_{2}\right)$ the ordinate of $\mathrm{D}$ is given by :

$$
V\left(M_{2} \geq M_{1}\right)=\frac{1_{1}-u_{2}}{\left(m_{2}-u_{2}\right)-\left(m_{1}-1_{1}\right)}
$$

To compare $M_{1}$ and $M_{2}$, both the values of $V\left(M_{1} \geq M_{2}\right)$ and $V\left(M_{2} \geq M_{1}\right)$ are required.

Step 3: The degree possibility for a convex fuzzy number to be greater than $k$ convex fuzzy number $\mathrm{M}_{\mathrm{i}}(\mathrm{i}=1,2, \ldots, \mathrm{k})$ numbers can be defined by:

$$
V\left(M \geq M_{1}, M_{2}, ., M_{k}\right)=V\left[\left(M \geq M_{1}\right) \text { and }\left(M \geq M_{2}\right) \text { and }\left(M \geq M_{k}\right)\right]=\min V\left(M \geq M_{i}\right), i=1,2, ., k
$$




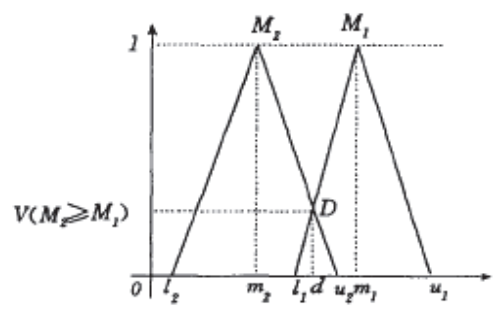

FIGURE 1. The Intersection Between $\mu_{\mathrm{M} 1}$ and $\mu_{\mathrm{M} 2}$

Step 4: Assume that $\mathrm{d}^{\prime}\left(\mathrm{A}_{\mathrm{i}}\right)=\min \mathrm{V}\left(\mathrm{S}_{\mathrm{i}} \geq \mathrm{S}_{\mathrm{k}}\right)$ for $\mathrm{k}=1,2, \ldots \mathrm{n} ; \mathrm{k} \neq \mathrm{i}$. Then, the weight vector is given by :

$$
W^{\prime}=\left(d^{\prime}\left(A_{1}\right), d^{\prime}\left(A_{2}\right), \ldots, d^{\prime}\left(A_{n}\right)\right)^{T}
$$

Where $A_{i}(i=1,2, \ldots, n)$ are $n$ elements.

Step 5: Via normalization, the normalized weight vectors are :

$$
W=\left(d\left(A_{1}\right), d\left(A_{2}\right), \ldots, d\left(A_{n}\right)\right)^{T}
$$

Where $\mathrm{W}$ is a non-fuzzy number that gives the priority weights of one criterion over another.

B. Grey TOPSIS

A multi-attribute group decision making model under the condition of uncertain information was proposed by [11] using baseline of grey number operations and Minkowski distance function and aggregation technique. Assuming a positive grey number matrix, Dk, be defined as :

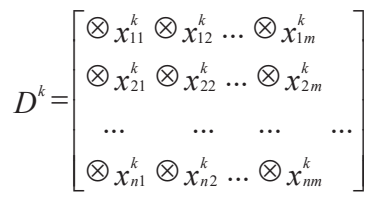

where $\otimes \mathrm{x}_{\mathrm{ij}}^{\mathrm{k}}$ denotes the grey evaluations of the $i$-th alternative with respect to the $j$-th attribute by decision maker $\mathrm{k}$ $(\mathrm{k}=1, \ldots \mathrm{K}) ; \otimes \mathrm{x}_{\mathrm{i}}^{\mathrm{k}}=\left(\otimes \mathrm{x}_{\mathrm{i} 1}^{\mathrm{k}}, \otimes \mathrm{x}_{\mathrm{i} 1}^{\mathrm{k}}, \ldots, \otimes \mathrm{x}_{\mathrm{im}}^{\mathrm{k}}\right)$ is the grey number evaluation series of the $i$-th alternative given by decision maker $k$. The proposed model procedure is explained in five steps.

Step 1: Construct the normalized grey decision matrices.

In general, the attribute property can be categorized into two types: (1) the larger-the-better; and (2) the smallerthe-better. The normalization of the larger-the-better type attribute can be written as:

$$
\otimes_{r_{i j}^{k}}=\frac{\otimes_{x_{i j}^{k}}}{\max \left(\bar{x}_{i j}^{k}\right)}=\left(\frac{\bar{x}_{i j}^{k}}{\max \left(\bar{x}_{i j}^{k}\right)}, \frac{\bar{x}_{i j}^{k}}{\max \left(\bar{x}_{i j}^{k}\right)}\right)
$$

While the normalization of the smaller-the-better type attribute can be calculated as:

$$
\otimes r_{i j}^{k}=\frac{\otimes x_{i j}^{k}}{\min \left(\bar{x}_{i j}^{k}\right)}+2=\left(\frac{-\bar{x}_{i j}^{k}}{\min \left(\bar{x}_{i j}^{k}\right)}+2, \frac{\bar{x}_{i j}^{k}}{\min \left(\bar{x}_{i j}^{k}\right)}+2\right)
$$

Step 2: Calculate the positive ideal alternative, $\mathrm{A}^{\mathrm{k}+}$, and the negative ideal alternative, $\mathrm{A}^{\mathrm{k}-}$, for each decision maker.

$$
\begin{aligned}
A^{k+}= & \left\{\left(\max r_{i j}^{-k} \mid j \in J\right),\left(\min r_{-i j}^{k} \mid j \in J^{\prime}\right) \mid i \in n\right\} \\
& =\left[r_{1}^{k+}, r_{2}^{k+}, \ldots, r_{m}^{k+}\right] \\
A^{k-} & =\left\{\left(\min r_{-i j}^{k} \mid j \in J\right),\left(\max r_{i j}^{-k} \mid j \in J^{\prime}\right) \mid i \in n\right\} \\
& =\left[r_{1}^{k-}, r_{2}^{k-}, \ldots, r_{m}^{k-}\right]
\end{aligned}
$$

Step 3: There are two sub-steps to be considered in step 3.

Step 3a. Determine the measures from the positive and negative ideal alternatives individually.

For decision maker $k$, the separation measures from the positive ideal alternative, $\mathrm{d}_{\mathrm{i}}^{\mathrm{k}+}$, and negative ideal alternative, $\mathrm{d}_{\mathrm{i}}^{\mathrm{k}-}$, are computed through weighted grey number minkowski distance as 


$$
\begin{aligned}
& d_{i}^{k+}=\left\{\frac{1}{2} \sum_{j=1}^{m} w_{j}\left[\left|r_{j}^{k+}-r_{-i j}^{k}\right|^{p}+\left|r_{j}^{k+}-r_{i j}^{-k}\right|^{p}\right]\right\}^{1 / p} \\
& d_{i}^{k}=\left\{\frac{1}{2} \sum_{j=1}^{m} w_{j}\left[\left|r_{j}^{k-}-r_{-i j}^{k}\right|^{p}+\left|r_{j}^{k-}-r_{i j}^{-k}\right|^{p}\right]\right\}^{1 / p}
\end{aligned}
$$

Step 3b. Aggregate the measures for the group. The group separation measure of each alternative for all decision makers will be aggregated through an operationn $\bigoplus$. The aggregation operation may use one of many choices, such as arithmetic mean, geometric mean, or their modification. Geometric mean is selected, and the group measures of each alternative will be

$$
\begin{aligned}
& d_{i}^{*+}=\left(\prod_{k=1}^{K} d_{i}^{k+}\right)^{1 / k}, \text { for alternative } i \\
& d_{i}^{*-}=\left(\prod_{k=1}^{K} d_{i}^{k-}\right)^{1 / k}, \text { for alternative } i
\end{aligned}
$$

Step 4: Calculate the relative closeness, $C_{i}^{*_{+}}$, to the positive ideal alternative for the group. The aggregation of relative closeness for the $i$-th alternative with respect to the positive ideal alternative of the group can be expressed as

$$
c_{i}^{*_{+}}=\frac{d_{i}^{*_{-}}}{d_{i}^{*_{+}}+d_{i}^{*_{-}}}
$$

where $0 \leq \mathrm{C}_{\mathrm{i}}^{*+} \leq 1$.

Step 5: Rank the preference order. A set of alternatives can now be preference ranked by the descending order of the value of $\mathrm{C}_{\mathrm{i}}^{*_{+}}$.

\section{METHODOLOGY}

This study integrated fuzzy AHP by [10] and Grey TOPSIS by [11] to solve multi-criteria decision making problem particularly for 3PL provider selection. Fuzzy AHP is used to calculate the importance weight of evaluation criteria. For final selection, grey TOPSIS is used to evaluate the alternatives and obtain the overall performance which is measured as closeness coefficient. Fuzzy AHP is integrated with grey TOPSIS by using the procedure shown in Fig. 2.

We emphasize that this problem follows group decision making. Therefore, the aggregation is strictly needed in order to obtain a single value both for sub-criteria weight and alternative performance. The point should be underlined for the aggregation procedure is there is a difference in aggregating between decision matrix of criteria weight and decision matrix of alternative performance. Using fuzzy AHP, decision matrices of criteria weight by $k$ decision makers were aggregated early right before normalization. Whereas, decision matrices of alternative performance constructed using grey TOPSIS were aggregated once the distance measure has been calculated. Arithmetic mean is used for aggregating criteria weight and geometric mean is used for aggregating alternative performance.

\section{RESULT AND DISCUSSION}

We implemented fuzzy AHP and Grey TOPSIS to evaluate and select 3PL provider for steel pipe company. There are four 3PL providers to be evaluated under the judgment of two decision makers. Evaluation is performed according to twelve sub-criteria which can be categorized into five criteria (see Table 1). 


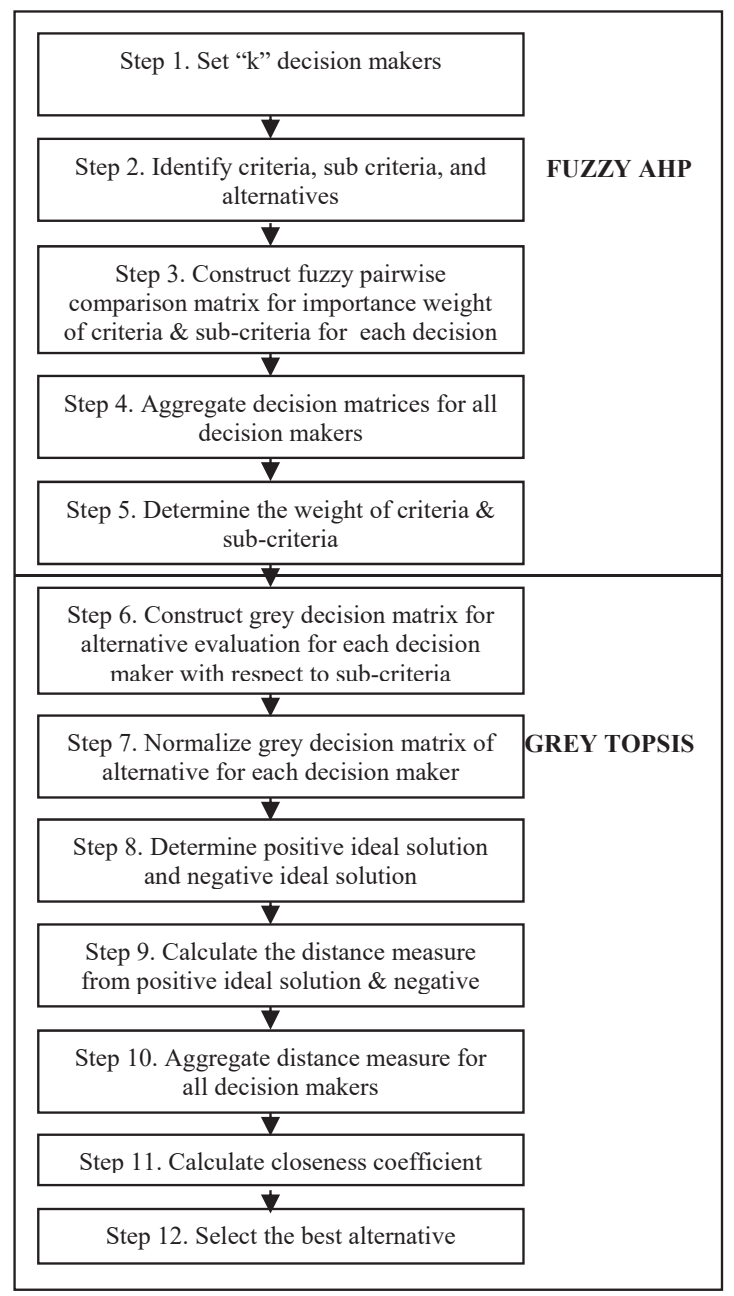

FIGURE 2. Methodology of The Study

TABLE 1. Evaluation Criteria For 3PL Provider

\begin{tabular}{|c|c|}
\hline Criteria & Sub-criteria \\
\hline \multirow[t]{2}{*}{ C1 Financial Performance } & SC1 Payment system \\
\hline & SC2 Financial stability \\
\hline \multirow[t]{3}{*}{ C2 Service Level } & SC3 Flexibility \& Responsiveness \\
\hline & SC4 Reliability \\
\hline & SC5 Timeliness \\
\hline \multirow[t]{3}{*}{ C3 Management } & SC6 Security \& Safety \\
\hline & SC7 Optimization Capabilities \\
\hline & SC8 Reputation and experience \\
\hline \multirow[t]{2}{*}{ C4 Client Relationship } & SC9 Long term Relationship \\
\hline & SC10 Information Sharing \\
\hline \multirow[t]{2}{*}{ C5 Operational Performance } & SC11 IT Capability \\
\hline & SC12 Size and Quality of fixed asset \\
\hline
\end{tabular}

The judgment of decision makers for importance weight of criteria and sub criteria are established by using pairwise comparison matrix. We used fuzzy Saaty's scale in order to express the level of comparison. The 
transformation of a crisp Saaty's scale into triangular fuzzy number (TFN) is performed in Table 2 [12]. The decision matrix for importance of criteria with respect to triangular fuzzy number is summarized in Table 3 . According to consistency ratio (CR), it implied that the decision makers' judgment is assured to fulfill the high consistency.

TABLE 2. Triangular Fuzzy Number For Criteria \& Sub Criteria

\begin{tabular}{ccc}
\hline Saaty's Scale & TFN & Reciprocal TFN \\
\hline 1 & $1,1,1$ & $1,1,1$, \\
2 & $1,2,3$ & $1 / 3,1 / 2,1$ \\
3 & $1,3,5$ & $1 / 5,1 / 3,1$ \\
4 & $2,4,6$ & $1 / 6,1 / 4,1 / 2$ \\
5 & $3,5,7$ & $1 / 7,1 / 5,1 / 3$ \\
6 & $4,6,8$ & $1 / 8,1 / 6,1 / 4$ \\
7 & $5,7,9$ & $1 / 9,1 / 7,1 / 5$ \\
8 & $6,8,9$ & $1 / 9,1 / 8,1 / 6$ \\
9 & $9,9,10$ & $1 / 10,1 / 9,1 / 9$ \\
\hline
\end{tabular}

TABLE 3. Triangular Fuzzy Judgment Matrix For Criteria

\begin{tabular}{cccccc}
\multicolumn{7}{c}{ TABLE 3. Triangular Fuzzy Judgment Matrix For Criteria } \\
\hline DM 1* & C1 & C2 & C3 & C4 & C5 \\
\hline C1 & $1,1,1$ & $1 / 3,1 / 2,1$ & $2,4,6$ & $3,5,7$ & $1 / 5,1 / 3,1$ \\
C2 & $1,2,3$ & $1,1,1$ & $1,3,5$ & $3,5,7$ & $1,1,1$ \\
C3 & $1 / 6,1 / 4,1 / 2$ & $1 / 5,1 / 3,1$ & $1,1,1$ & $1,2,3$ & $1 / 7,1 / 5,1 / 3$ \\
C4 & $1 / 7,1 / 5,1 / 3$ & $1 / 7,1 / 5,1 / 3$ & $1 / 3,1 / 2,1$ & $1,1,1$ & $1 / 8,1 / 6,1 / 4$ \\
C5 & $1,3,5$ & $1,1,1$ & $3,5,7$ & $4,6,8$ & $1,1,1$ \\
\hline DM 2** & $\mathbf{C 1}$ & $\mathbf{C 2}$ & $\mathbf{C 3}$ & $\mathbf{C 4}$ & $\mathbf{C 5}$ \\
\hline C1 & $1,1,1$ & $1 / 5,1 / 3,1$ & $1 / 3,1 / 2,1$ & $1 / 3,1 / 2,1$ & $1,1,1$ \\
C2 & $1,3,5$ & $1,1,1$ & $1,3,5$ & $1,1,1$ & $2,4,6$ \\
C3 & $1,2,3$ & $1 / 5,1 / 3,1$ & $1,1,1$ & $1 / 5,1 / 3,1$ & $1,3,5$ \\
C4 & $1,2,3$ & $1,1,1$ & $1,3,5$ & $1,1,1$ & $4,6,8$ \\
C5 & $1,1,1$ & $1 / 6,1 / 4,1 / 2$ & $1 / 5,1 / 3,1$ & $1 / 8,1 / 6,1 / 4$ & $1,1,1$ \\
\hline *CONSISTENCY RATIO DM1 $(\mathrm{CR})=0.072, * * \mathrm{CR}$ DM $2=0.069$ &
\end{tabular}


TABLE 4. Triangular Fuzzy Judgment Matrix For Sub Criteria

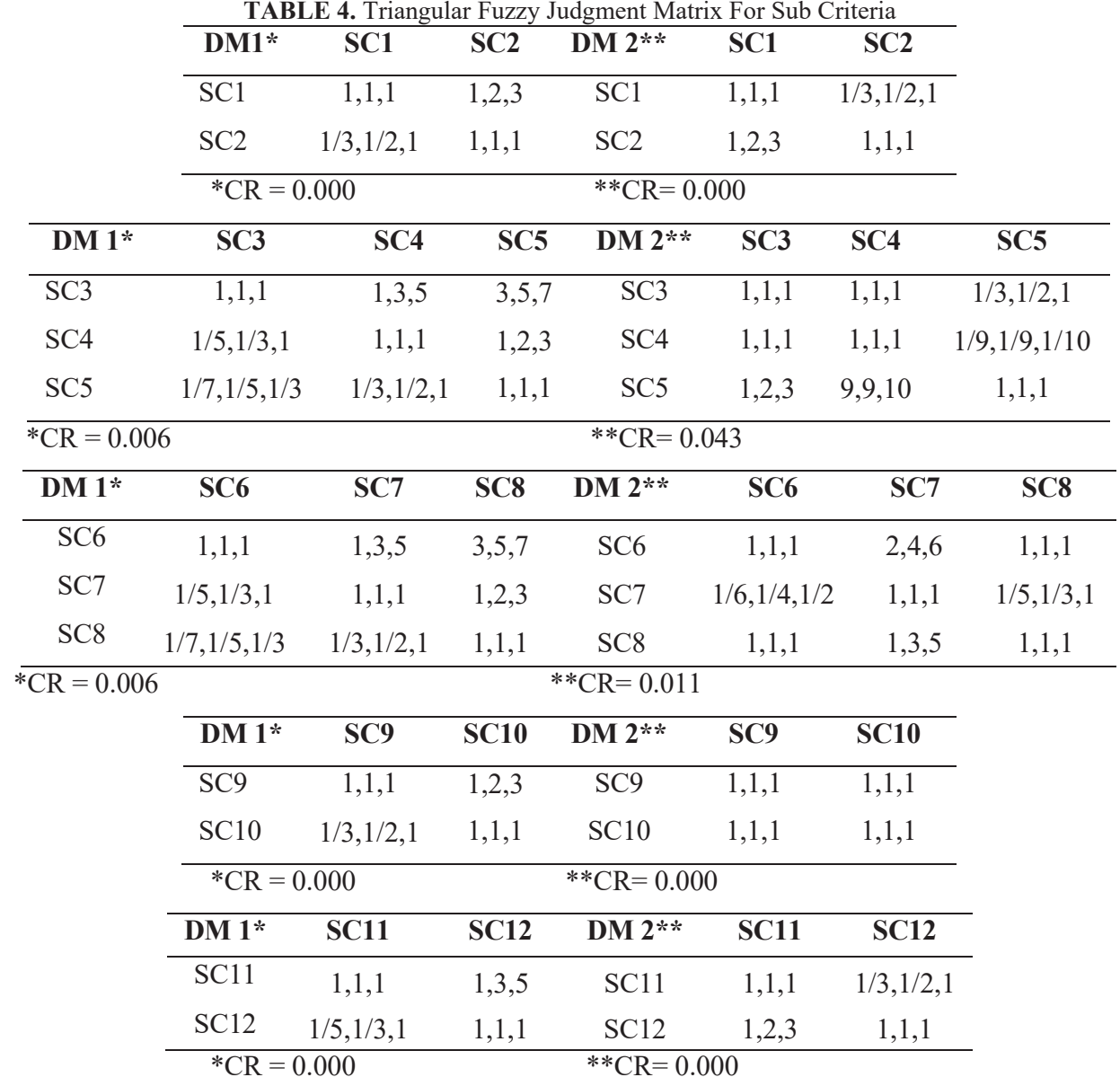

Using the fuzzy AHP proposed by [10], we obtained the global weight of sub-criteria. Table 5 shows criteria and sub criteria weight and its ranking.

TABLE 5. Sub Criteria Weight and Ranking

\begin{tabular}{|c|c|c|c|c|}
\hline Criteria & Weight & Sub- criteria & Weight & Rank \\
\hline \multirow[t]{2}{*}{$\mathrm{C} 1$} & 0.035 & $\mathrm{SC} 1$ & 0.017 & 6 \\
\hline & & $\mathrm{SC} 2$ & 0.017 & 6 \\
\hline \multirow[t]{3}{*}{$\mathrm{C} 2$} & 0.480 & SC3 & 0.207 & 2 \\
\hline & & $\mathrm{SC} 4$ & 0.066 & 4 \\
\hline & & SC5 & 0.207 & 2 \\
\hline \multirow[t]{3}{*}{$\mathrm{C} 3$} & 0.021 & SC6 & 0.012 & 7 \\
\hline & & SC7 & 0.004 & 10 \\
\hline & & SC8 & 0.006 & 9 \\
\hline \multirow[t]{2}{*}{$\mathrm{C} 4$} & 0.030 & SC9 & 0.020 & 5 \\
\hline & & $\mathrm{SC} 10$ & 0.009 & 8 \\
\hline \multirow[t]{2}{*}{$\mathrm{C} 5$} & 0.434 & SC11 & 0.235 & 1 \\
\hline & & $\mathrm{SC} 12$ & 0.200 & 3 \\
\hline
\end{tabular}


Then, four 3PL providers are evaluated under those sub-criteria. The evaluation of alternatives is able to incorporate the transition of known-unknown information which most likely can't be declared into a precise form. Therefore, that is going to be unconfident judgment. Using grey number for evaluation is meaningful since it used interval value. Grey TOPSIS was used to relaxing the decision maker's judgment without lack of determination. The linguistic variable for alternative evaluation using Grey TOPSIS is shown in Table 6 [12]. Two decision makers evaluated four 3PL providers for each sub-criteria which are summarized in Table 7.

Because twelve sub-criteria are the larger-the-better type, the alternative evaluation of each decision maker is normalized using (8). In order to measure the overall performance of the alternative, we should ensure the relative distance how close to the best value and how far from the worst value for each sub criteria. The distance measure of alternative with respect to positive ideal solution $\left(\mathrm{d}_{\mathrm{i}}^{\mathrm{k}+}\right)$ and negative ideal solution $\left(\mathrm{d}_{\mathrm{i}}^{\mathrm{k}-}\right)$ are calculated using (12) and (13) with $\mathrm{p}=2$. The result can be shown in Table 8 .

TABLE 6. Linguistic Variable and Corresponding Grey Number

\begin{tabular}{lclc}
\hline Linguistic Variable & $\begin{array}{c}\text { Grey } \\
\text { Number }\end{array}$ & Linguistic Variable & $\begin{array}{c}\text { Grey } \\
\text { Number }\end{array}$ \\
\hline Very Poor (VP) & $0-1$ & Medium Good (MG) & $5-6$ \\
Poor (P) & $1-3$ & Good (G) & $6-9$ \\
Medium Poor (MP) & $3-4$ & Very Good (VG) & $9-10$ \\
Medium (M) & $4-5$ & & \\
\hline
\end{tabular}

TABLE 7. Alternative Evaluation From Two Decision Makers

\begin{tabular}{ccccc}
\hline $\begin{array}{c}\text { Sub- } \\
\text { criteria }\end{array}$ & $\begin{array}{c}\text { Provider A } \\
\text { DM1/DM2 }\end{array}$ & $\begin{array}{c}\text { Provider B } \\
\text { DM1/DM2 }\end{array}$ & $\begin{array}{c}\text { Provider C } \\
\text { DM1/DM2 }\end{array}$ & $\begin{array}{c}\text { Provider D } \\
\text { DM1/DM2 }\end{array}$ \\
\hline $\mathrm{SC} 1$ & $\mathrm{MG} / \mathrm{G}$ & $\mathrm{G} / \mathrm{G}$ & $\mathrm{MG} / \mathrm{MG}$ & $\mathrm{M} / \mathrm{MG}$ \\
$\mathrm{SC} 2$ & $\mathrm{G} / \mathrm{MG}$ & $\mathrm{G} / \mathrm{G}$ & $\mathrm{MG} / \mathrm{G}$ & $\mathrm{MG} / \mathrm{MG}$ \\
$\mathrm{SC} 3$ & $\mathrm{G} / \mathrm{MG}$ & $\mathrm{VG} / \mathrm{VG}$ & $\mathrm{MG} / \mathrm{MG}$ & $\mathrm{VG} / \mathrm{VG}$ \\
$\mathrm{SC} 4$ & $\mathrm{G} / \mathrm{MG}$ & $\mathrm{G} / \mathrm{G}$ & $\mathrm{G} / \mathrm{M}$ & $\mathrm{G} / \mathrm{G}$ \\
$\mathrm{SC} 5$ & $\mathrm{MG} / \mathrm{MG}$ & $\mathrm{MG} / \mathrm{G}$ & $\mathrm{G} / \mathrm{M}$ & $\mathrm{G} / \mathrm{G}$ \\
$\mathrm{SC} 6$ & $\mathrm{G} / \mathrm{MG}$ & $\mathrm{MG} / \mathrm{MG}$ & $\mathrm{M} / \mathrm{G}$ & $\mathrm{MG} / \mathrm{G}$ \\
$\mathrm{SC} 7$ & $\mathrm{G} / \mathrm{MG}$ & $\mathrm{G} / \mathrm{MG}$ & $\mathrm{MG} / \mathrm{MG}$ & $\mathrm{G} / \mathrm{G}$ \\
$\mathrm{SC} 8$ & $\mathrm{MG} / \mathrm{MG}$ & $\mathrm{G} / \mathrm{G}$ & $\mathrm{MG} / \mathrm{G}$ & $\mathrm{MG} / \mathrm{MG}$ \\
$\mathrm{SC} 9$ & $\mathrm{G} / \mathrm{G}$ & $\mathrm{VG} / \mathrm{VG}$ & $\mathrm{MG} / \mathrm{MG}$ & $\mathrm{MG} / \mathrm{M}$ \\
$\mathrm{SC} 10$ & $\mathrm{MG} / \mathrm{MG}$ & $\mathrm{G} / \mathrm{G}$ & $\mathrm{M} / \mathrm{M}$ & $\mathrm{MG} / \mathrm{M}$ \\
$\mathrm{SC} 11$ & $\mathrm{MG} / \mathrm{MG}$ & $\mathrm{MG} / \mathrm{VG}$ & $\mathrm{MG} / \mathrm{MG}$ & $\mathrm{G} / \mathrm{VG}$ \\
$\mathrm{SC} 12$ & $\mathrm{VG} / \mathrm{MG}$ & $\mathrm{VG} / \mathrm{G}$ & $\mathrm{MG} / \mathrm{M}$ & $\mathrm{MG} / \mathrm{G}$ \\
\hline
\end{tabular}

This problem is a group decision making where there are two decision makers. Thus, we must aggregate the distance measure to obtain single value. Aggregate the evaluation of each $d_{i}^{k+}$ and $d_{i}^{k-}$ for $k=1,2$ to calculate $d_{i}^{*+}$ and $d_{i}^{*-}$ using (14) and (15), respectively, e.g.,

$$
\begin{aligned}
& \mathrm{d}_{\mathrm{A}}^{*_{+}}=(0.599 \times 0.789)^{1 / 2}=0.688 \\
& \mathrm{~d}_{\mathrm{A}}^{*_{-}}=(0.882 \times 0.660)^{1 / 2}=0.763
\end{aligned}
$$


TABLE 8. Individual and Aggregation of Distance Measure

\begin{tabular}{ccccccc}
\hline Alternatives $i$ & \multicolumn{2}{c}{ DM 1 } & \multicolumn{2}{c}{ DM 2 } & \multicolumn{2}{c}{ AGGREGATION } \\
& $\mathrm{d}_{\mathrm{i}}^{1+}$ & $\mathrm{d}_{\mathrm{i}}^{1-}$ & $\mathrm{d}_{\mathrm{i}}^{2+}$ & $\mathrm{d}_{\mathrm{i}}^{2-}$ & $\mathrm{d}_{\mathrm{i}}^{*+}$ & $\mathrm{d}_{\mathrm{i}}^{*-}$ \\
\hline Provider A & 0.599 & 0.882 & 0.789 & 0.660 & 0.688 & 0.763 \\
Provider B & 0.469 & 1.052 & 0.394 & 1.141 & 0.430 & 1.096 \\
Provider C & 0.902 & 0.482 & 0.856 & 0.677 & 0.879 & 0.571 \\
Provider D & 0.738 & 0.758 & 0.755 & 0.834 & 0.747 & 0.795 \\
\hline
\end{tabular}

Finally according to aggregated distance measure of $\mathrm{d}_{i}^{*_{+}}$and $\mathrm{d}_{\mathrm{i}}^{*_{-}}$, we have a relative closeness for each alternative $\left(\mathrm{C}_{\mathrm{i}}^{+}\right)$obtained from the calculation in the following. The relative closeness indicates the closeness from the ideal positive solution. The larger the index value, the better evaluation of alternatives will be with respect to whole sub-criteria.

$$
\begin{aligned}
& \mathrm{C}_{\mathrm{A}}^{*+}=\frac{\mathrm{d}_{\mathrm{A}}^{*-}}{\mathrm{d}_{\mathrm{A}}^{*_{+}}+\mathrm{d}_{\mathrm{A}}^{*_{-}}}=\frac{0.763}{0.688+0.763}=0.526 \\
& \mathrm{C}_{\mathrm{B}}^{*_{+}}=\frac{\mathrm{d}_{\mathrm{B}}^{*_{-}}}{\mathrm{d}_{\mathrm{B}}^{*_{+}}+\mathrm{d}_{\mathrm{B}}^{*_{-}}}=\frac{1.096}{0.43+1.096}=0.718 \\
& \mathrm{C}_{\mathrm{C}}^{*+}=\frac{\mathrm{d}_{\mathrm{C}}^{*-}}{\mathrm{d}_{\mathrm{C}}^{*_{+}}+\mathrm{d}_{\mathrm{C}}^{*_{-}}}=\frac{0.571}{0.879+0.571}=0.394 \\
& \mathrm{C}_{\mathrm{D}}^{*+}=\frac{\mathrm{d}_{\mathrm{D}}^{*-}}{\mathrm{d}_{\mathrm{D}}^{*+}+\mathrm{d}_{\mathrm{D}}^{*}}=\frac{0.795}{0.747+0.795}=0.516
\end{aligned}
$$

According to the closeness coefficient $\left(\mathrm{C}_{\mathrm{i}}^{+}\right)$, it is evident that the most compromised solution is alternative $\mathrm{B}$ which means Provider B is selected as the best alternative. The rank order of alternative based on the closeness coefficient for more detail is summarized in Table 9.

TABLE 9. Relative Closeness of Each Alternatives and Alternative Ranking

\begin{tabular}{ccc}
\hline Ranking & Alternative 3PL Provider & $\mathbf{C}_{\mathbf{i}}^{+}$ \\
\hline 1 & Provider B & 0.718 \\
2 & Provider A & 0.526 \\
3 & Provider D & 0.516 \\
4 & Provider C & 0.394 \\
\hline
\end{tabular}

\section{CONCLUSION}

The decision making problem in accordance with 3PL provider selection can be tackled sophisticatedly by using integration of Fuzzy AHP and Grey TOPSIS. This approach can enhance the unconfident judgment caused by vague and grey information. The triangular fuzzy number represents the vagueness in determination of criteria importance weight. Further, grey number, utilized in TOPSIS, is employed to alternative evaluation when grey information detracts the confidence level of judgmental opinion.

A case study in terms of 3PL provider evaluation is a crucial problem since that activity involving inbound and outbound process can be a direct impact to the long terms existence of the factory. Therefore, 3PL provider should be evaluated thoroughly in order to support the continuity of business process particularly to manage the flow of raw material and product to customer. Evaluation criteria have been identified that are financial performance, service level, management, client relationship and operational performance. Those criteria have been compiled more detail representing sub-criteria. Finally 3PL providers were evaluated under 12 sub-criteria. Considering more criteria in 
evaluating 3PL providers will be confusing if the inappropriate approach is used. The decision might cause the solution to be inappropriate. This can be overcame by applying a sophisticated decision making approach. Using Fuzzy AHP and Grey TOPSIS offers the most appropriate decision for 3PL provider. The result shows that selected $3 \mathrm{PL}$ which is the most compromising alternative can satisfy overall criteria evaluation.

\section{REFERENCES}

1. G. Akman, and K. Baynal, "Logistics service provider selection through an integrated fuzzy multicriteria decision making approach," Journal of industrial engineering, 2014

2. S. Jharkharia, and R. Shankar, "Selection of logistics service provider: An analytic network process (ANP) approach," Omega, Vol. 35, pp. 274-289, 2007.

3. H. Göl, and B. Catay, "Third-party logistics provider selection:insights from a Turkish automotive company," Supply Chain Management: An International Journal, vol. 12, pp. 379-384, 2007.

4. S-H. Soh, "A decision model for evaluating third-party logistics providers using fuzzy analytic hierarchy process," African Journal of Business Management, vol. 4, pp. 339-349, March 2010.

5. S. Datta, C. Samantra, S.S. Mahapatra, G. Mandal, and G. Majumdar, "Appraisement and selection of third party logistics service providers in fuzzy environment," Benchmarking: An International Journal, vol. 20, pp. 537-548, 2013.

6. S. Percin, "Evaluation of third-party logistics (3PL) providers by using a two-phase AHP and TOPSIS methodology," Benchmarking: An International Journal, vol. 16, pp. 588-604, 2009.

7. V. Ravi, "Selection of third-party reverse logistics providers for End-of-Life computers using TOPSIS-AHP based approach,” International Journal of Logistics Systems and Management, vol.11, pp. 24-37, 2012.

8. J.L. Deng, "The introduction of grey system," The Journal of Grey System, vol. 1, pp. 1-24, 1989.

9. G-D. Li, D. Yamaguchi, and M. Nagai, "A grey-based decision-making approach to the supplier selection problem,” Mathematical and Computer Modelling, vol. 46, pp. 573-581, 2007.

10. D-Y. Chang, "Applications of the extent analysis method on fuzzy AHP," European Journal of Operational Research, vol. 95, pp. 649-655, December 1996.

11. Y-H. Lin, P-C. Lee, T-P. Chang, and H-I. Ting, "Multi-attribute group decision making model under the condition of uncertain information', Automation in Construction, vol. 17, pp. 792-797, August 2008.

12. T.E. Saputro, and B. Erdebilli, "A hybrid approach for selecting material handling in a warehouse," International Journal of Managemens Science \& Engineering Management, vol. 11, pp. 34-48, January 2016. 